\title{
ANALOGÍA Y COMUNICACIÓN (INTERPELACIÓN, DIÁLOGO INTERCULTURAL HACIA LA TRANSMODERNIDAD)
}

Prof. D. Enrique Dussel ${ }^{1}$

Profesor Emérito de la UAM

(México)

La comunicación unívoca es posible cuando el significado de las palabras o los signos son abstractos. Así el enunciado matemático " $2+2=4$ ” es unívoco y de precisión extrema. Si le agregamos la cualidad a la mera cantidad del número, se trata del grado (por ejemplo: 2 grados de temperatura más otros 2 son 4 grados), cada uno de ellos son unívocos en su identidad numérica aunque el último enunciado sea más complejo. Pero cuando se enuncia "2 flores", y en referencia de una hacia otra, ya no nos permite predicar que "la flor 1 es idéntica a la flor 2", sino que el significado de un término de la relación se refiere al otro singular con diferencia ${ }^{2}$ individual.

En el caso de la comunicación humana, cuando un ser humano se comunica con otro acerca de su mundo ontológico, biográfico, histórico, propio, la enunciación pierde igualmente y en mayor medida su univocidad, porque el horizonte de sentido 3 (la “comprensión del ser" diría M. Heidegger, que no es idéntico al de otros mundos) da a todos los entes del mundo un cierto sentido distinto (que es lo que se intenta comunicar en el diálogo existencial entre personas). Ello lleva a ciertos filósofos a hablar de la inevitable incomunicabilidad, por la

\footnotetext{
${ }^{1}$ Véase www.enriquedussel.com

2 En este trabajo hay tres palabras que serán usadas con precisión semántica: 1) la palabra "diferencia" (differentia en latín) se refiere a la identidad unívoca, 2) la "distinción” (distinctio) a la semejanza analógica, y 3) la "diversidad" (diversitas) indica la no-igualdad del significado de las dos anteriores.

${ }^{3}$ El "significado" (relación semántica) indica la referencia de la palabra o el concepto a la cosa (sea real o de razón): el "sentido" (relación ontológica) (sens en francés, Sinn en alemán, sense en inglés) indica la respectividad de la cosa o el significado a la totalidad del mundo.
} 
inconmensurabilidad ontológica de los mundos de los sujetos de enunciación. Estaríamos aquí en el caso opuesto a la univocidad matemática; es decir, se trataría de la equivocidad cuasi absoluta de la incomunicabilidad, aunque se enuncie la misma palabra ${ }^{4}$ no se tiene un significado idéntico (por lo que se opina que la palabra del que la enuncia es incomprensible para el oyente, pretendiendo una comprensión unívoca, con identidad). Por el contrario, defenderemos que puede haber una comprensión por semejanza, pero no idéntica, de la misma palabra en cada uno de los mundos de los interlocutores, ya que la expresión de uno puede tener en el mundo del otro un significado distinto aunque semejante ${ }^{5}$, y por lo tanto aproximadamente comprensible (que podría aumentar la mutua comprensión por el diálogo en el "tiempo de la analogía"6).

Y bien, entre la univocidad que supone una simplificación del contenido semántico de lo que se comunica, y la equivocidad de lo diverso sin común significado, debemos situar el uso de la analogía que hace referencia a una razón comunicativa que permita mayor flexibilidad, riqueza de contenido y posibilidad de entablar un diálogo entre mundos o realidades humanas que se cumplen en el proceso de la temporalidad, diacrónicamente: comienza por la mínima comprensión mutua y va creciendo por la ampliación del campo semántico común donde la acción hermenéutica de la palabra del otro va haciéndose cargo cada vez de manera más cabal y profunda del significado de las palabras y del mundo del otro. La semejanza se acerca a la identidad sin jamás coincidir con ella, como en el caso de una línea asintótica (el momento 3 del siguiente diagrama indica la imposible identidad).

$\mathrm{Ni}$ la total univocidad del consenso idéntico o monosémico que comprende clara y precisamente a las diferencias, ni la inconmensurabilidad de la incomprensión como imposibilidad de la comunicación puramente equívoca, sino el polisémico ámbito analógico de la semejanza que permite un consenso o acuerdo que sin embargo admite el respeto tolerante de la comprensión por distinción analógica del Otro/a.

\footnotetext{
${ }^{4}$ Por ejemplo, cuando se comunica: “¡Te amo!” a la pareja.

5 ¿Pueden tener acaso los interlocutores de un diálogo la misma interpretación del sentido del “amor”? Quizá, para uno, significa el servirse del otro para cumplir sus apetitos egoístas (el mero éros); en cambio, para el otro, puede significar la amistad en el muto servicio (la filía); y aún podría ser un afecto incondicional y desinteresado en la construcción de la felicidad del Otro (el agápe) sin buscar retorno: amar aún sin ser amado. Al expresar, todavía sin explicación: “-¡Te amo!”, no se tiene certeza de coincidir con el Otro/a en su significado. ¡Es todavía un riesgo, un acto de fe (que explicaremos en la analogia fidei!

${ }^{6}$ Indicado con $t$ en el diagrama 1.
} 


\section{Diagrama 1}

Entre la equivocidad y la plena identidad comunicativa se encuentra el tiempo de la comunicación en la semejanza de la analogía

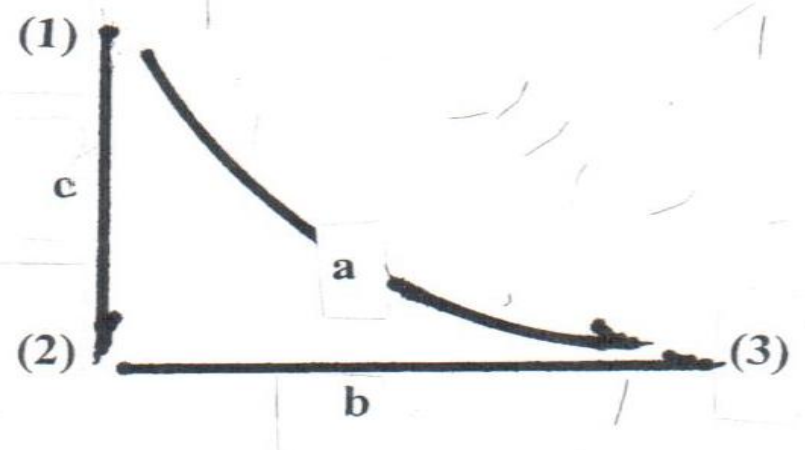

Aclaración al diagrama 1: Los límites del proceso de la comunicación son los extremos (1) y (3), entre los que se cumple la semejanza en torno a la que se practica el diálogo comunicativo, como en el caso de una línea asintótica (flecha a) que indica el aumento de la semejanza analógica, la que no coincide con la incomunicabilidad equívoca (1) ni con la perfecta comunicación unívoca (3). Ese avanzar en el “tiempo de la comunicación" (flecha $b$ ), aunque no se llega a la imposible identidad (2), permite una mayor comprensión (de la flecha c hacia 3) a través de la creciente "fusión de horizontes" (del tipo analizado por H. Gadamer, ver el diagrama 5).

A la lógica de la totalidad con identidad/diferencia unívoca le opondremos la lógica de la alteridad con semejanza/distinción analógica. Aún más brevemente: a la razón unívoca moderna se la confrontará con la razón análoga exigida en toda comunicación interhumana, y muy especialmente en el diálogo intercultural planetario hoy tan necesario.

Además, expondremos, a manera de ejemplos, el uso de la analogía en algunos temas de actualidad: la posibilidad de interpretar la interpelación del Otro/a en situaciones existenciales cotidianas, y con mayor exigencia en acontecimientos críticos; la posibilidad del indicado diálogo intercultural, tan necesario para superar la univocidad del eurocentrismo moderno y despejar el horizonte hacia una descolonización epistemológica. Y el tratamiento de nociones tenidas por ambiguas, tales como pueblo en la filosofía política, que aplicándoles la lógica de la analogía transforman su aparente ambigüedad en la claridad de diversas 
distinciones analógicas que tienen una cierta semejanza y distintos analogados, uno principal de donde se desprenden los distintos significados de los analogados derivados (que no consisten en la mera "familiaridad de palabras").

\section{Olvido de la analogía en la modernidad}

Si efectuamos un repaso histórico podemos observar que hubo momentos fuertes en el uso de la analogía, y otros momentos en que casi desapareció. Tuvo mucha presencia desde los

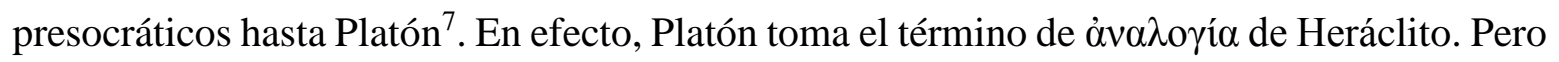
quien la consagra definitivamente es Aristóteles.

El origen del término entonces es griego, principalmente usado en la matemática, y posteriormente ampliando su uso a otras temáticas, tal es el caso aristotélico (y de allí después se proyectarán a otras escuelas helenistas). El Estagirita escribe que: "El ser se dice de muchas maneras" ( $\tau$ ò òv $\left.\lambda \varepsilon^{\prime} \gamma \varepsilon \tau \alpha \iota \pi 0 \lambda \lambda \alpha \chi \tilde{\omega} \varsigma\right)^{8}$. Ese "se dice" ( $\left.\lambda \varepsilon ́ \gamma \varepsilon \tau \alpha \iota\right)$ nos sitúa en el nivel de la palabra, del término, de la denominacionalidad (decibilidad) de lo lingüístico, objeto de la filosofía del lenguaje.

Sin embargo, el tema de la analogía, al decir de Paul Ricoeur, fue descuidado por el linguitic turn, y esto debe explicarse.

Desearía desde el comienzo mostrar un diagrama (como los que Charles Peirce acostumbraba diseñar, ya que un ícono tiene un significado conceptual), y nada mejor para representar sincrónicamente la complejidad de la cuestión de la analogía. Se trata de la diversidad entre la analogía y la univocidad de la identidad.

En primer lugar, entonces, situemos la identidad/diferencia para compararla con la diversidad de la analogía/distinción.

\section{Diagrama 2}

\footnotetext{
${ }^{7}$ E. Jüngel, Zum Ursprung der Analogie bei Parmenides un Heraklit, Walter de Gruyter, Berlin, 1964.

${ }^{8}$ Metafísica Z, 2, 1003 a 33. Para el Estagirita había cuatro maneras distintas de denominar o predicar al ser: como "accidente" ( $\sigma \nu \mu \beta \varepsilon \beta \eta \kappa o ́ \varsigma)$; como "potencia" y "acto"; como "verdad" y según el "esquema de las categorías" (Metaf., E, 2, 1026 a 34ss).
} 


\section{Diversos componentes del concepto lógico de Identidad/Diferencia. La univocidad}

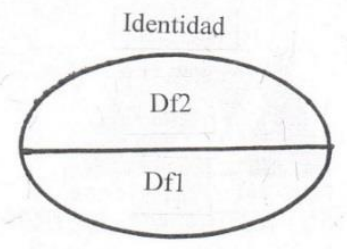

Aclaración al diagrama 2. La Identidad comprende dentro de su horizonte semántico múltiples Diferencias (Df1: Diferencia 1; Df2: Diferencia 2; etcétera). En signos matemáticos de conjuntos se podría expresar así: la "Identidad" se da como Totalidad de las Diferencias internas: Identidad = Diferencia $1+$ Diferencia 2 + etcétera. La Diferencia no tiene alteridad de fundamento con respecto a la Identidad. En la comunicación cuando se usan palabras unívocas se cae en la tautológica, ya que el horizonte de la Identidad es el mismo para las Diferencias. El modelo de la comunicación de R. Jacobson supone esta identidad tautológica en la comunicación (el mensaje codificado por un comunicador es decodificado por el que recibe tal mensaje; no hay dificultad en la tal decodificación porque ambos suponen tener el mismo significado; la "pretensión de inteligibilidad" de J. Habermas también supone la identidad unívoca).

Los componentes mínimos del concepto de univocidad son la identidad, como el todo significado, y la diferencia. Habrá entonces que considerar el momento de la identidad (Id) (en griego $\tau o ̀ ~ \alpha u \tau o ́{ }^{9}$, en latín identitas, en francés identité, en inglés identity, en alemán Identität) como lo común, y el momento de lo diverso de toda diferencia $(D f)$ (esta última se

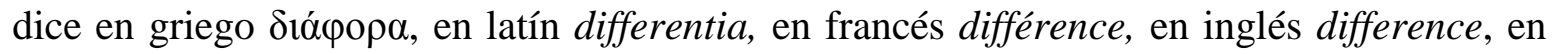
alemán Unterscheidung ${ }^{10}$ ).

En el pensamiento griego la identidad del ser se impuso sobre la analogía ya que "el Uno" o "el Ser", aunque puede decirse analógicamente del ente, son en cuanto tal (es decir, en cuanto Uno o Ser) lo mismo que sí mismo: son unívocos, idénticos. El Ser no es análogo, sino que se predica analógicamente del ente (en latín lo expresaríamos: analogia entis). El ser unívoco se dice analógicamente de la ousía, de la cualidad, de la cantidad, de la relación,

\footnotetext{
${ }^{9}$ Aristóteles, Metaf., E, 1, 1018 a 12.

${ }^{10}$ También se usa la palabra de etimología latina Differenz.
} 
etcétera. Los entes no son el Ser, pero son sus distinciones; es decir, modos distintos de predicar lo mismo: el Ser.

Esta lógica de la univocidad se encuentra también en las ontologías del continente indostánico o chino, y en parte en los pueblos originarios de América (en doctrinas como las del Upanishad, Laotze, Confucio, en la palabra Pacha en quechua o aymara entre los Incas, y en otros numerosos pueblos). Serían tradiciones unívocas del universo (y debería incluirse por ejemplo a un B. Spinoza entre estas posiciones).

La problemática cambia con el mundo semita que comprende el ser mismo de manera analógica (analogia essendi) que se predica de un creador del universo y de las creaturas. Un Filón de Alejandría se enfrenta a esta dificultad: el creador es y se le predica el ser, lo mismo acontece con las creaturas que son, los entes, y se les predica también el ser. Ahora el "Ser mismo" se dice de dos maneras: como del Ser eterno, creador, y como el ser del ente, creado. Ha mediado una nueva comprensión del ser mismo. Por ello aparece una tensión entre dos polos: la creatura y el creador; es decir, la totalidad creada (A), y la alteridad creadora (B); dicha analogía se sitúa en el horizonte de lo sagrado (no necesariamente de lo religioso).

\section{Diagrama 3}

\section{Totalidad/Alteridad}

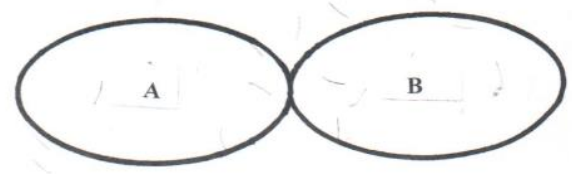

Aclaración al diagrama 3. A: la totalidad ontológica, con identidad unívoca. B: La exterioridad como alteridad trans-ontológica, el Otro/a.

Desde los pueblos acadios, babilónicos, palestinos, con influencia en Egipto, con los fenicios, hebreos, cristianos y musulmanes, la lógica de la analogía solucionó esta problemática que no había sido estudiada con precisión en la Eurasia indoeuropea ni en la América originaria, aunque hay claro indicios de su existencia. 
Es por ello que los semitas debieron transformar la doctrina de la analogía del ente griega en la analogía del Ser mismo.

Los filósofos cristianos de los primeros siglos d.C. (llamados los Padres de la Iglesia, desde la Escuela de Alejandría, en especial con Orígenes), y después los árabes (desde Al Kindi en Alepo en el siglo IX d.C.), echaron mano de la analogía de una manera radicalmente diversa a la de los griegos. Este pensamiento experimenta al ser de las creaturas (mediando la propuesta de un acto radical de creación ex nihilo, en latín desde Tertuliano ${ }^{11}$; y como ouk ex

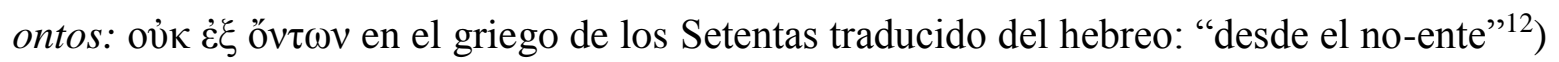
como "distinto" de la eminencia (eminentia) del Ser del creador. Se entiende entonces que cuando se acepta la lógica helenista dentro del pensamiento judeo-cristiano en el Mediterráneo oriental a partir del siglo II d.C., se crea la nueva figura lógica de la "analogía del Ser" mismo (analogia essendi). El manejo de esta analogía culmina en la filosofía bizantina, que pasa a ser usada por los árabes musulmanes como en el caso de Avicena (desde Samarkanda a Bukhara), pasando por la Bagdad de un Al’Farabi y El Cairo fatimita, hasta Averroes (en el Califato de Córdoba y en la ciudad berebere de Fes por un Maimónides), y llegando muy tardíamente a la Edad Media latino-germánica en el París en el siglo XIII, en la figura de los grandes maestros tales como Tomás de Aquino, para culminar posteriormente en Duns Scoto.

Una nueva etapa creativa de la analogía se produce en la modernidad, en la época del Renacimiento con las filosofías de Thomas de Vio Cayetano, Silvestre de Ferrara hasta Juan de Santo Tomás en el siglo XVII español.

Repasemos resumidamente lo hasta ahora ganado.

\section{Diagrama 4}

Distintos componentes del concepto lógico de Semejanza/Distinción. La analogía

\footnotetext{
${ }^{11}$ Véase Dussel, El dualismo en la antropología de la cristiandad, Guadalupe, Buenos Aires, 1974.

${ }^{12}$ Macabeos II, 7, 28. El texto completo dice: "que Yahveh los ha hecho desde el no-ente y que la raza de los hombres fue hecha de la misma manera". Es así que el "orden político vigente" no es eterno sino creado, y puede ser transformado cuando es injusto. Se es así ateo o no-fetichista del orden dominador.
} 


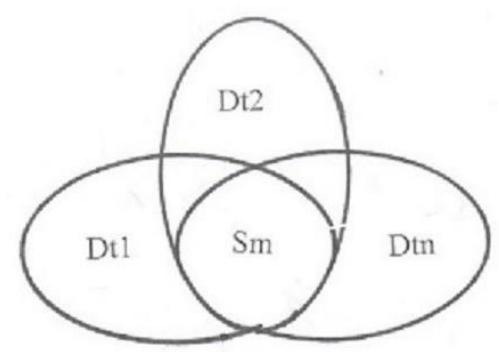

Aclaración al diagrama 4: Sm: Semejanza; Dt1: Distinción analógica 1; Dt2: Distinción analógica 2;

Dtn: otras Distinciones analógicas. En signos matemáticos de conjuntos se podría expresar la "Semejanza", lo común o la coincidencia entre los analogados distintos de la siguiente manera:

"Semejanza = Distinción analógica $1 \cap$ distinción analógica $2 \cap$ distinción analógica $n$. A medida que la comunicación aumenta la semejanza $(\mathrm{Sm})$ se va llenando de mayor significado, sentido, sin perderse la diversidad ${ }^{13}$ de la peculiar distinción analógica (Dt1, Dt2, Dtn) de cada uno de los analogados.

La lógica analógica distinguió diversos tipos de analogía, la de atribución intrínseca o de proporcionalidad, cada una con varias subdivisiones internas. Quizá en los siglos XVI y XVII esta doctrina llegó a su máxima complejidad ${ }^{14}$. En esta corta contribución no podemos entrar a tratar este tema en toda su diversidad.

Los componentes lógicos esenciales son dos, y se denominan a) la semejanza ( $\mathrm{Sm}$ ), en griego con la palabra ö $\mu o_{0}$, similitudo en latín, Ähnlichkeit en alemán, ressemblance en francés, similarity en inglés, y b) la distinción $(D t)$ que no tiene una traducción tan usual en griego ni tampoco en alemán ${ }^{15}$ (aunque podríamos eventualmente elegir Verschiedenartichkeit), aunque sí tiene un término propio en latín con la palabra distinctio, en francés distinction o en inglés distinction.

${ }^{13}$ Hemos ya indicado que no debemos identificar tres palabras: diferencia, distinción y diversidad, que nos muestra no equivalencia de diferencia y distinción. J. Derrida intentó distinguir, con un nuevo significado, différence de différance. Por mi parte, desde comienzo de la década del 70 del siglo XX pasado, y como crítica a Derrida, indiqué que era mejor usar la palabra distinción analógica que différance, pero llevó a muchos malos entendidos por la ignorancia de la doctrina de la analogía (como la crítica de mi exdcelente colega Ofelia Schutte). Véase Dussel, Philosophy of Liberation, 2.2.5 y 2.4.3 (Orbis Books, New York, 1985).

${ }^{14}$ Par una introducción autorizada sobre la cuestión nada mejor que la de Philibert Secreten, L'analogie, PUF, Paris, 1984; y también de Mauricio Beuchot, Hermenéutica, analogía y símbolo, Herder, México, 2004 (puede considerarse la extensa obra de Beuchot sobre la hermenéutica analógica en internet); además L. Bruno Puntel, Analogie und Geschichtlichkeit, Herder, Freiburg, 1969.

${ }^{15}$ Esto nos manifiesta una cierta imprecisión entre los autores que han tocado el tema. 
Todo el secreto y la utilidad de la analogía se encuentra en poder hacer un buen uso en las prácticas de comunicación entre mundos diversos (sean singulares o colectivos) y en enfrentamientos retóricos donde debe saberse elegir las palabras (las oraciones, las sentencias, los “juegos de lenguajes” [speech acts], etcétera) e interpretar convenientemente la significación de las expresiones del Otro/a para la mutua y adecuada compresión en la comunicación. Debe entonces considerarse la diversidad claramente de a) la semejanza (Sm) polisémica de b) la identidad (Id) monosémica, y de c) la distinción analógica (Dt) (que tiene semejanza con las restantes distinciones) de d) la mera diferencia (Df) (de lo diverso dentro del horizonte de la identidad). Por otra parte, la diversidad de la distinción (con otras distinciones) no es equivalente a la mera ambigüedad equívoca, que por su parte no debe confundirse tampoco con la diversidad de los componentes de la semejanza analógica ni con la de la "familiaridad de las palabras" en la lingüística de un Wittgenstein ${ }^{16}$. La pura noidentidad, que no es diferente ni tiene tampoco distinción analógica, es lo diverso en absoluto: lo equívoco. Lo equívoco es más diverso (tiene exclusivamente la palabra en común, pero no su significado) que lo distinto de lo semejante, y lo distinto de lo semejante es más diverso (no tiene tanto en común) que lo diferente situado dentro del horizonte de lo idéntico $^{17}$.

Los estudios y el uso de la analogía, entonces, han recorrido un largo camino desde Platón o Aristóteles hasta el mismo Hegel en el siglo XIX o Max Müller en pleno siglo XX, y por ello su contenido fue cambiando históricamente. En la etapa de la Eurasia indoeuropea estuvo determinada por ciertos límites ontológicos. En este pensamiento en general, y el de los griegos en particular, el ser se predica analógicamente de los entes como hemos dicho, pero el ser mismo no era análogo, sino unívoco, ya que se predicaba de sí mismo con identidad.

Los autores modernos del norte de Europa utilizarán secundariamente, en cuestiones parciales, la analogía en sus reflexiones lógicas, lo mismo un Kant que un $\mathrm{Hegel}^{18}$, aunque no será una cuestión central filosófica tan debatida como en la llamada Edad Media, ya que

\footnotetext{
${ }^{16}$ La “familia de palabras" es menos común que la semejanza; es solo una cierta igualdad etimológica o terminológica pero de menor consistencia estrictamente semántica. Cuando es denominacional (palabra) y semántica (conceptual) puede ser semejanza analógica.

${ }^{17}$ Es decir, lo equívoco es lo absolutamente no-común; lo semejante es lo en parte común; lo idéntico es lo absolutamente común (Kovvós).

${ }^{18}$ Véase la obra ya nombrada de Bruno Puntel, cuyo título completo es Analogie und Geschichtlichkeit. Philosophiegeschichtlich-Kritischer Versuch über das Grundproblem der Metaphysik, 1969.
} 
la secularización dejará de tratar la relación creador-creatura y con ello la "analogía del Ser" mismo.

Renacerá la problemática con un Franz Brentano ${ }^{19}$, y dentro de la renovación de la escuela neoescolástica, relanzada en las universidades de Freiburg y Louvain, especialmente con pensadores que se sitúan desde el horizonte de la ontología preponderantemente alemana como J. Maréchal ${ }^{20}$, J. Lotz ${ }^{21}$, K. Rahner ${ }^{22}$, E. Coreth ${ }^{23}$ y un B. Lakebrink ${ }^{24}$, G. Siewerth ${ }^{25}$ o E. Przywara ${ }^{26}$, que desarrollan el concepto de analogía en el siglo XX. Pero seguirá siendo un pensamiento secundario que no penetrará en el centro de la discusión de la linguistic turn del Círculo de Viena ${ }^{27}$. Esto último debido a que el pensamiento centro-europeo o anglosajón, desde la Ilustración, se situará dentro de la univocidad de la identidad/diferencia, en parte debido al proceso indicado y creciente de secularización (es decir, el Ser del creador desaparece del horizonte de la reflexión filosófica). La analogía no cuenta ya como un tema relevante en la filosofía más estudiada por la comunidad filosófica europea o norteamericana.

\section{De la analogía del ente (analogia entis) a la analogía de la palabra (analogia verbi)}

Es muy diverso el punto de partida de la relación cuando el ser o el ente son los que se refieren a la palabra (a), que cuando es la palabra el punto de partida de la referencia al ser o el ente (b):

a) Referencia del ser o ente a la palabra (del ser o el ente $\longrightarrow$ a la palabra)

b) Referencia de la palabra al ser o al ente (de la palabra $\longrightarrow$ al ser o el ente)

19 Von der mannigfachen Bedeutung des Seienden nach Aristoteles (1862), Wissenschaftliches Buchgesellschaft, Darmstadt, 1960, punto de partida de la filosofía de M. Heidegger.

${ }^{20}$ Le point de départ de la métaphysisque, Cahier V, Museum Lessianum, Paris-Bruselas, 1949.

${ }^{21}$ Die Transzendentale Methode in Kants Kritik der rienen Vernunft, en Kant und die Scholastik heute (1955) pp. 35-108.

${ }^{22}$ Geist und Welt. Zur Metaphysik der endlichen Erkenntnis bei Thomas v. Aquin, Herder, Munc0hen, 1957; Hörer des Wortes, Herder, München, 1963.

${ }^{23}$ Metaphysik. Eine metodisch-systematische Grundlegung, Tyrolia, Innsbruck, 1961.

${ }^{24}$ Hegels dialektische Ontologie und die Thomistische Analektik, Ratingen/Düsseldorf, 1968.

25 Die Analogie des Seienden, Johannes Verlag, Einsiedeln, 1965

${ }^{26}$ Analogia Entis, 1939, Johannes Verlag, Einsiedeln, 1962

${ }^{27}$ Véase Rudolf Teuwsen, Familienähnlichkeit und Analogie, Verlag Karl Alber, Freiburg, 1988. 
Todo lo dicho hasta ahora expresa la relación $(a)$ : del ser o el ente hacia la palabra; es decir, la palabra significa, expresa, manifiesta al ser, al ente, a la cosa. Se trata de la relación de significación. Pero ahora deseamos iniciar un camino inverso poco transitado entre los autores antiguos y actuales que tratan de la analogía, y representado por la relación $(b)$.

En efecto, como una corriente secundaria y un tanto descuidada, un miembro del Idealismo alemán pasa del "Sistema de la Identidad" (llama la atención la claridad de la denominación usada como un sistema de la identidad, es decir, de la univocidad) a una metafísica de la libertad (cuyos primeros pasos se inician en 1809), que se expresan como una doctrina de la voluntad, y que se manifiesta plenamente en sus lecciones universitarias de Berlín en 1841 como crítica al pensar hegeliano. Se trata de F. Schelling en sus Vorlesungen über die Offenbarung. Allí se expone el horizonte desde el cual se podrá entender lo que llamaríamos, en primera instancia, una doctrina de la analogía de la palabra: la analogia verbi. Ya no se sitúa la problemática exclusivamente desde la "analogía del ser" (analogía essendi) (a), sino que comenzará a pensarse la "analogía de la palabra" $(b)^{28}$.

El punto de partida de la nueva implantación de la analogía se origina en la alteridad. Alter nos habla del Otro/a que trasciende la totalidad del mundo propio ("mundo" en el sentido hegeliano para Schelling, o el mundo existencial heideggeriano como horizonte ontológico del que se ocupa E. Levinas ${ }^{29}$ ). Sin embargo, Levinas tiende a situar al Otro como “absolutamente Otro", como una trascendentalidad que pareciera reverenciar y aceptar la infinita distancia de la equivocidad del Infinito. Al descubrir la prioridad y superioridad de la alteridad pareciera situarse ante lo incomprensible, lo incomunicable, lo sagrado que interpela. Por ello, al leer la obra levinasiana se despertó la pregunta de si la interpelación del Otro era comprensible, descifrable, interpretable, lo que exigiría una cierta semejanza entre el decir (le Dire) que interpela en lo dicho (le dit) desde la alteridad trascendente y lo que decodifica o interpreta el oyente; es decir, la posibilidad de la captación del que escucha, del que oye, del que "tiene oídos para oír" de un significado verdaderamente significativo (es

\footnotetext{
${ }^{28}$ Palabra que en griego se traducía por $\lambda$ óyos, y en semita, hebreo (דבר, dabar). A esta problemática se refiere la expresión: "La Palabra (דבר; dabar) devino carne (בשר; basar)" (Juan, 1, 14). Véase mi obra E. Dussel, El humanismo semita, Eudeba, Buenos Aires, 1969 (www.enriquedussel.com/obras).

${ }^{29}$ La obra clásica de Levinas Totalité et Infinit. Essaie sur la Exteriorité, Ed. Nijhoff, La Haya, 1961, tematiza ese "más allá del ser" ( a udelà de lê̂tre), del mundo de Heidegger, de la ontología. Todo esto lo hemos expresado desde 1970 en numerosas obras que no refiero aquí (véase www.enriquedussel.com/obras).
} 
decir, que el oyente/obediente pueda captar, comprender, descifrar el significado de la palabra del Otro). Y en ese momento, para matizar el equivocidad trascendental absoluta del Otro, nació la necesidad de volver a recurrir a la "lógica de la analogía": el Otro, meta-físico, ético, real, interpela con palabras que se pueden al menos comprender derivadamente o interpretar de alguna manera; es decir, que se alcance inicialmente ${ }^{30}$ a efectuar una hermenéutica por semejanza con lo dicho por el Otro desde su decir (la mera presencia de la corporalidad desnuda del Otro: ¡Ecce homo! anterior a toda palabra, a las experiencias de la vida del mundo del que escucha. La palabra del Otro tiene como significado una cierta distinción semántica con las palabras del mundo del oyente, pero gracias a la analogía (que no es unívoca ni equívoca) se puede ir acercando a su significado ${ }^{31}$ por semejanza; es decir, a un cierto significado de alguna manera común. F. Schelling expuso la necesidad del a priori de la "revelación" (Offenbarung: la Palabra expresada por el Otro ante el que la escucha obediente) como fuente del a posteriori conocimiento, refiriéndose preferentemente al Absoluto. Levinas amplía la fenomenología de la revelación como epifanía teniendo también en cuenta la revelación del Otro/a antropológico, y especialmente del Otro como existiendo en la mayor alteridad posible del mundo del oyente, en el caso del destituido, del sufriente, de "la viuda, del huérfano, del pobre, del extranjero", expresiones presentes en el Código de Hammurabi semita hace 3700 años ${ }^{32}$.

Las primeras expresiones del Otro, del oprimido, del excluido, del negado son las indescifrables interjecciones, todavía no palabras, proto-palabras, de un: “-¡Ayyyy!”; el grito de dolor del sufriente, que deviene en las distintas exposiciones interpelantes del torturado, del esclavo crucificado (como Espartaco o el fundador del mesianismo cristiano), de la mujer dominada por el machismo, del indígena martirizado por el conquistador en el siglo XVI en América Latina, del obrero asalariado por el capitalismo moderno europeo y en el mundo colonial del Sur, etcétera.

\footnotetext{
${ }^{30}$ Momento (1) del diagrama 1.

${ }^{31}$ Momento (3) asintótico del mismo diagrama 1.

${ }^{32}$ Cuestiones que ya traté en 1961 en mi obra El humanismo semita (EUDEBA, Buenos Aires, 1969), después de mi estadía de dos años en Israel de 1959 a 1961.
} 
Situados en un nivel antropológico (no del Infinito $^{33}$ sino del ser humano) ante la revelación (la Offenbarung schellingiana) de la "palabra del Otro/a", y partiendo de dicha palabra en búsqueda de su significado (se trata de la relación $b$ indicada más arriba: de la palabra hacia el ser, hacia el significado: analogia verbi), la analogía cobra una relevancia central, porque la mayoría de las expresiones significativas existenciales de la vida cotidiana, en especial el diálogo que se entabla entre interlocutores distintos y de diversos campos de acción o praxis (sean políticos, económicos, de géneros, etcétera), todas usan obviamente la analogía y no la identidad unívoca.

Lo que un H. G. Gadamer llama "fusión de horizontes"34 es exactamente el proceso de crecimiento de la semejanza que comienza, en un primer momento, desde una mayor o menor incomunicabilidad o incomprensión en la comunicación (como la defendida por algunos comunitaristas anglosajones ${ }^{35}$ ), y puede incrementarse aumentando la semejanza por el diálogo, aunque nunca se llegará a una identidad plena entre los interlocutores (es la flecha a del diagrama 1 al comienzo de este trabajo, que indica el pasaje de 1 a 3 ).

\section{Diagrama 5}

"Fusión de horizontes" o la comunicación en la lógica de la analogía

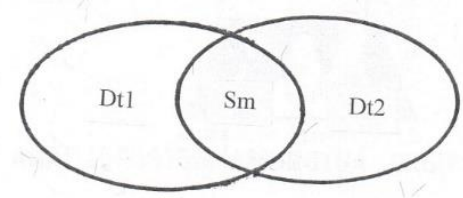

\footnotetext{
${ }^{33}$ La implantación de la analogía con respecto al Ser creador semita la pongo filosóficamente entre paréntesis; no la niego, pero no la sitúo como el referente principal filosófico de la analogía, teniendo en cuenta un mundo secular. Si la postsecularización avanza podremos tratar igualmente ese tema, pero aquí no es esencial todavía. 34 "En el análisis del proceso hermenéutico la obtención del horizonte de la interpretación es en realidad una fusión de horizontes" (Véase Verdad y método, III, 12, 2; Sígueme, Salamanca, 1988, p. 477). Escribe todavía Gadamer que el "espacio de fusión" va en "aumento" en lo que ambos mundos tienen de "semejante" gracias al transcurso del tiempo el diálogo: "Si uno se desplaza [para comprender] a la situación del otro ser humano, uno lo comprenderá, esto es, se hará consciente de su alteridad, de su singularidad irreductible, precisamente porque es uno mismo el que se separa de su situación. Este desplazarse [...] significa siempre un ascenso hacia una semejanza superior, que rebasa tanto la singularidad propia como la del otro" (Ibid., II, ii, 9, 4; p. 379)). Es exactamente la función de la semejanza de la analogía y no la fusión (como exclusión del Otro/a) de la universalidad unívoca que exige la sumisión del Otro/a a la identidad del enunciado del ego que expande su mismidad como diferencia interna: se pretende subsumir al Otro/a en el mundo del sí mismo aniquilando la alteridad.

${ }^{35}$ Véase mi Ethics of Liberation, 1.3 (Duke University Press, Durham, 2013).
} 
Cuadernos Filosóficos. Segunda Época, XIV, 2017

Aclaración al diagrama 5. Sm) La semejanza analógica que va creciendo a medida que los dialogantes se van asumiendo el mundo del Otro/a. Dt1 y Dt2) Puntos de partida de la mutua revelación desde su exterioridad (secreto, misterio). Aunque Dt1 y Dt2 permanecen distintos (no diferentes en la identidad que los dominaría, sino distintos analógicamente que los deja ser sí mismos en la semejanza) van aumentando su comunidad en el diálogo (la comunidad es lo que tienen de común, de semejantes).

La analógica "fusión de horizontes" de los mundos de los dialogantes le permite a los que participan en la comunidad de comunicación ser sí mismos y distintos, siendo cada vez más comunidad en la semejanza (en la verdad pluriversal), más allá de la equivocidad de la indiferencia del Otro/a y más acá de la dominación de la identidad (en donde uno de los dialogantes ha sido subsumido por el opresor que impone su verdad idéntica, unívoca, con pretensión de universalidad) ${ }^{36}$.

Por todo ello la lógica de la analogía se muestra como imprescindible en las experiencias de diálogo en los más diversos niveles, desde el horizonte concreto de personas singulares, pero muy especialmente en los procesos comunitarios y sociales, económicos, políticos, de género, de raza, etcétera, en los que estamos involucrados.

\section{La analogia fidei ${ }^{37}$}

La experiencia metafísica (que frecuentemente escribimos meta-física para indicar la diversidad con la mera metafísica del realismo ingenuo), es para E. Levinas la ética en cuanto tal, que se origina en el cara-a-cara (en hebreo se escribe panim el panim:פנים אל פנים) del rostro de una persona ante el rostro de otra persona sin mediación alguna, nos sitúa ante el problema de la analogia fidei que es un desarrollo más complejo que el de la analogia verbi. En el origen del diálogo o de la comunicación cotidiana, existencial o personalizada, cuando

\footnotetext{
${ }^{36}$ La lógica de la univocidad es diversa a la lógica de la analogía. Sobre el tema estamos escribiendo una obra en la línea de otras acerca del método analéctico de la Filosofía de la Liberación. Véase E. Dussel, Para una ética de la liberación latinoamericana, § 36, Siglo XXI, Buenos Aires, 1973, vol. 2, pp. 156ss (hay una traducción francesa de este texto: "Pensée analectique en Philosophie de la Libération", en P. Gisel-Ph. Secretan, Analogie et dialectique, Labor et Fides, Genêve, 1982, pp. 93-119); E. D., Método para una Filosofía de la Liberación latinoamericana, Sígueme, Salamanca, 1974, o en E.D., Philosophy of Liberation, ya citada; pueden consultarse estas obras y otras en www.enriquedussel.com/obra o /work). Sobre mi posición en la cuestión de la analéctica consultar Ph. Secretan, en L'Analogie, op. cit., pp. 69-76.

37 Véase el § 36: "El método analéctico y la filosofía latinoamericana", en mi obra Para una ética de la liberación latinoamericana (1973), Siglo XXI, México-Buenos Aires, 2014, pp. 156-174.
} 
los interlocutores no se conocen todavía, cuando el Otro/a se expresa inicialmente (la epifanía primera), la revelación (o la palabra del Otro/a como comunicación de la intimidad que debe exponer su misterio, su mismidad, lo que es en lo más íntimo y que no se expone $e^{38}$ frecuentemente por temor a su utilización contra el que se revela) no puede todavía ser descifrada plenamente. Cuando el Otro/a se revela dando cuenta de algo secreto de su mundo, el que recibe esa palabra temblorosa capta solo parte del contenido semántico expuesto. No se trata de un concepto inmediatamente interpretado de manera unívoca por el oyente interpelado; no puede desde el primer momento descifrar el contenido semántico de esa palabra del mundo del Otro/a; es solo una primera aproximación.

Si un necesitado dice a un interlocutor: “¡¡Tengo hambre, dame de comer!” ¿Tiene su hambre el mismo significado que el hambre del interpelado? ¿Tiene el interpelado la certeza del sentido de dicha hambre que funda honestamente una interpelación ética? ¿Pide de comer porque no desea trabajar, o porque es un drogadicto y porque necesita dinero, o porque es un limosnero profesional y está engañando a los que interpela? ¿Y si el que oye la palabra del necesitado se dispone a darle de comer, cumplirá con la justicia o promoverá el vicio de la vagancia en el limosnero? ¿Si no tenía certeza empírica de la existencia objetiva de la necesidad accidental o estructural de esa pobreza, podrá cumplir un acto justo dando una limosna?

Aquí estamos en presencia de un acto cotidiano de extrema densidad. El que responde con un acto a la interpelación suplicante del Otro/a, que tiene ante sí solo la presencia empírica del pobre que se revela primeramente en su rostro por un "decir" (sin necesidad aun de "lo dicho"), no puede exigir pruebas por la urgencia de la circunstancia ante la responsabilidad de cumplir el deber de darle de comer. En ese caso, debe entonces "tomar como verdadera" (für Wahr halten) la palabra del Otro/a, y darle de comer a partir de la fe, de la con-fianza que despierta la veracidad que se manifiesta (un fenómeno), que aparece fenomenológicamente en el rostro del Otro/a que se presenta como la epifanía de un ser

\footnotetext{
${ }^{38}$ En castellano, español, "exponerse" significa no solo "darse a conocer" sino igualmente arriesgarse a permanecer en público, cuando esa confrontación puede significarle al "expuesto" ser atacado, ser malentendido, ser agredido. "Exponerse" en este sentido, y ante mi pregunta a E. Levinas en la Universidad de Louvain (Bélgica) en 1972, de ¿qué significaba "exposición”? (termino técnico usado por él en sus escritos), el filósofo francés abrió su chaqueta con sus dos manos y "expuso" su pecho diciéndome: “- ¡Como cuando uno se expone ante un pelotón de fusilamiento!"
} 
humano (no mera aparición fenomenológica de un ente-alguien, no algo) a través de la palabra suplicante. No cumple el acto el que con-fìa (con-fe) motivado, movido, justificado por el probado conocimiento empírico de la necesidad del Otro/a, sino porque cree a/en la persona, y por ello le atribuye validez a la palabra creída como verdadera que ocupa el lugar del conocimiento de un hecho empírico (que puede constatarse a posteriori por pruebas y concluir la existencia de la verdad del contenido de la interpelación, para que se cumpla un acto de auténtica justicia). Mientras tanto la fe fue el fundamento (ratio) suficiente de tal acción. Y así el alimento es donado desde y sobre la palabra del Otro/a debido a la urgencia ética. Es decir, el creer en su honestidad, no todavía probada como un hecho empírico plenamente probado, conocido, se funda en el acto de la voluntad que mueve o impera a la razón práctica a efectuar esa acción, esa limosna, ese don ${ }^{39}$.

La filosofía medieval describía a la fe o el acto de creer como el acto cuyo fundamento lo constituía la voluntad, siendo el origen o la motivación de la decisión cuyo desenlace permite la posibilidad del acto cognitivo (assentire) que se alcanzará a posteriori la interpretación de lo dicho por el interpelante, y de lo que no tuvo el interpelado, al comienzo, un conocimiento pleno unívoco del contenido o significado de lo que cognición futura, y este pasar del querer (consentire) a la intelección sin demostración probatoria está debido a la urgencia de la situación:

El asentir (adherir) propiamente pertenece al intelecto [intellectus...]; mientras que el consentir (querer) pertenece propiamente a la voluntad (voluntatis), porque consentir es como sentir-con-el-otro." "Creer [...] no tiene asentimiento [cognitivo] sino bajo el imperio de la voluntad ${ }^{41}$.

Es decir, la voluntad al mover a creer a/en el Otro/a, a/en su persona, impone el contenido de la palabra enunciada al acto cognitivo; es decir, sustituye la evidencia de la prueba

\footnotetext{
${ }^{39}$ Claro que un Mao Tse-tung, desde la pedagogía neoconfuciana de Wang Yang-ming, recomendaría: “-¡No le regales un pescado, sino enséñale a pescar!"

40 "Et ideo assentire proprie pertinent ad intellectum, quia importat absolutam adhaerentiam ei cui assentitur; sed consentire est proprie voluntatis quia consentire est simul cum alio sentire" (Thomas de Aquino, De Veritate, q. 14, a. 1, resp; Marietti, Torino, 1964, p. 281 a).

41 "Credere autem [...] non habet assensum nisi ex imperio voluntatis" (Ibid., a. 3; p. 287 a). "Cum igitur fides sit in intellectu secundum quod est motus et imperatus a voluntate" (Ibid., a. 5; p. 291 a).
} 
demostrativa empírica posible (de lo dicho no verificado todavía) por una decisión querida que moviliza la acción; mueve o motiva a la inteligencia por un acto de la voluntad que acepta el contenido de la palabra desde la confianza depositada en el Otro/a como fundamento suficiente para efectuar la praxis consecutiva requerida.

Es decir, de no haber una cabal conceptualización en el interpelado del significado de la palabra proferida por el Otro/a interpelante, no habría tampoco posibilidad de efectuar una acción a su servicio que necesita urgentemente. Sería necesaria una verificación previa, una conceptualización probada de la verdad de la palabra y de la veracidad del necesitado suplicante para tomar una decisión. En el caso del acto de fe racional, la razón es movida, para romper el impase de la imposibilidad de la acción sin haber alcanzado su pleno conocimiento en la identidad, por otro fundamento que el mero conocimiento de lo a obrar. En efecto, la motivación voluntaria, afectiva, el amor-de-justicia propia del sistema límbico sobre el sistema neocortical (diría un neurólogo especialista del cerebro $^{42}$ ), moviliza al interpelado gracias a la fe por la que cree en la persona del Otro/a desde el reconocimiento de su dignidad (porque lo jerarquiza desde un amor de alteridad intersubjetiva), lo que mueve a la inteligencia a aceptar como si fuera ya probada la verdad de la palabra del Otro/a. Repitiendo. El que recibe la revelación del Otro/a desde la apertura de su subjetividad creyente efectúa una acción porque cree, porque tiene fe en la palabra del Otro/a ante la imposibilidad de poder verificar (en una primer instancia) la verdad de lo que se le ha sido revelado. A la lógica que explica este hecho la llamaremos analogia fidei, porque es la fe en el Otro/a lo que permite aceptarla como razón (Grund) o fundamento del acto, con anterioridad de la plena captación del concepto de la palabra del Otro/a. que todavía no ha sido justificado racional ni discursivamente por la subjetividad cognitiva del interpelado. F. Schelling expuso alguna reflexiones sobre el tema en sus clases universitarias Sobre la revelación que deseamos aplicarlas, en un nivel antropológico, cuando escribe que toma "la revelación en primer lugar como una auténtica fuente de conocimiento (Erkenntnisquelle)" 43. Y todavía expresa:

\footnotetext{
${ }^{42}$ Como por ejemplo Antonio Damasio, Descates' error. Emotion, Reason, and the Human Brain, Putnam Book, New York, 1994.

${ }^{43}$ Philosophie der Offenbarung, Lección 24; Werke, ed. Schröter, Becksche Verlag, München, 1959, VI, p. 398.
} 
"La sabiduría, a la que todo el trabajo del saber se encamina como a su fin, la llamamos fe (Glaube) [...] La fe no debe ser representada como un saber infundado, sino que más bien habría que decir que es lo mejor fundado de todo [das allerbegründetste], porque ella tiene aquello, ante lo cual es vencida toda duda, tan absolutamente positivo, que toda superación hacia otro término es imposible" ${ }^{44}$.

El momento analógico se juega también simultáneamente gracias al hecho por el que la razón capta la interpelación, la revelación, la palabra del Otro/a desde la semejanza semántica mínima que posee esa palabra en el mundo del interpelado. Sabe lo que es tener hambre; sabe que el hambre se satisface con alimento; no tiene claridad semántica de qué tipo de hambre se trata en concreto, ni de cuál sea el origen y sentido del hambre del que lo interpela, pero por semejanza (fusión mínima de horizontes) aproximadamente capta o interpreta semánticamente su contenido. El dolor expresado en su rostro lo mueve, toca su sensitividad $^{45}$, su afectividad, su voluntad. Tendrá tiempo, el tiempo del crecimiento de la captación del significado analógico de la palabra semejante del Otro/a, de llegar a un mejor entendimiento, consenso, comunicación, captación cognitiva del contenido de la palabra gracias al diálogo futuro. Así podrá entender mejor el tipo y el origen de esa hambre. Sin embargo, nunca habrá una captación, conceptuación o interpretación completamente unívoca o idéntica entre los dos dialogantes del significado de la palabra proferida en la interpelación inicial. El sentido del hambre del Otro/a nunca será el hambre, idéntico, unívoco del Otro/a.

La fe en la persona del Otro/a, y por ello de su palabra, abre entonces en la inicial fusión de horizontes mínima la captación de una semejanza analógica que la voluntad de comunicación permitió desde el respeto y el amor-de-justicia sagrado a la persona del Otro/a. De esta manera la analogía permite que la razón discursiva crezca de una semejanza mínima hasta una mayor comprensión mutua que el tiempo del dialogo irá acrecentando. Pero

\footnotetext{
${ }^{44}$ Ibid., p. 407. Hemos aplicado en la antropología un texto con intención teológica en Schelling. En el plano humano es posible "pasar a otro término"; es el "tiempo del diálogo". En este sentido la revelación del otro/a es epifanía del misterio de la exterioridad de lo que guarda en su intimidad el Otro/a. Véase Dussel, Filosofía de la Liberación (1977), 2.4.7.3; FCE, México, 2014, p. 86.

${ }^{45}$ Véase mi artículo sobre E. Levinas, "Sensitivity and Otherness in Emmanuel Levinas", en Philosophy Today (Chicago), Summer (1999), pp. 129-234.
} 
además, la revelación del Otro/a como interpelación a la justicia pone en cuestión la totalidad ontológica unívoca y la relanza a una creación dialéctica de lo nuevo, de lo inesperado y no planeado por la totalidad vigente. Por ello escribíamos en 1973:

Esa revelación del Otro/a [...como interpelación a la justicia] ha cuestionado el nivel ontológico que es ahora recreado desde un nuevo ámbito. El discurso se hace ético y el nivel fundamental ontológico [unívoco] se descubre como no originario, como abierto desde lo ético [el Otro/a como exterioridad analógica] que se revela después (ordo cognoscendi a posteriori) como lo que era antes (el prius del ordo realitatis) [...] La aceptación del Otro/a como otro supone ya una opción ética, una elección y un compromiso ético: es necesario negarse como totalidad, afirmarse como finito, ser ateo del fundamento como identidad ${ }^{46}$.

Con la pasión de una obra juvenil escribía en aquel tiempo:

Si la filosofía fuera solo teoría, comprensión refleja del ser e interpretación pensada del ente, la palabra del Otro/a sería indefectiblemente reducida a lo ya dicho e interpretado equívocamente desde el fundamento vigente de la Totalidad [de mi Totalidad...]. Tomar la palabra del Otro/a como unívoca de la propia es la maldad ética del fanático, falta ética que lo condena porque es el error capital de la inteligencia [...] Considerar la palabra del Otro/a en la semejanza a las de mi mundo, conservando su distinción meta-física que se apoya en él/ella como Otro/a, es respetar la analogía como revelación; es cumplir con el deber de comprometerse en la humildad ${ }^{47}$ para la felicidad del Otro/a.

\section{La analogía del concepto polisémico de "pueblo"}

Es una antigua polémica en la filosofía política latinoamericana que guarda todavía actualidad $^{48}$. ¿Qué o quién es el pueblo? ¿Cuál es su función en la política? ¿Cuándo nace, crece o entra en crisis? ¿No será que es una palabra o un concepto a tal grado complejo que

\footnotetext{
${ }^{46}$ Para una ética de la liberación latinoamericana, § 36; II, pp. 162-163. Véase Dussel, Método para una Filosofía de la Liberación, 1974, § 17, pp. 116ss.

${ }^{47}$ Ibid., pp. 170-171.

48 Véase mi artículo “Cinco tesis sobre el populismo”, en E. Dussel, Filosofías del Sur. Descolonización y Transmodernidad, Akal, México-Madrid, 2015 (pp.219-246).
} 
es mejor abandonarlo para no agregar confusión a un tema por sí mismo ambiguo? Pienso que la lógica de la analogía es el camino metódico para la solución de esa controversia en la filosofía política, y muy especialmente en la Filosofía de la Liberación.

Para algunos el concepto de pueblo es ambiguo, contradictorio, escurridizo, y por ello no sirve como categoría de interpretación política (como opina Horacio Cerutti). Otros prefieren, inspirándose en B. Spinoza, y elaborar el concepto de multitud y niegan el de pueblo (como Antonio Negri). Es también escogida como una categoría válida, pero en la vertiente semántica del populismo (como Ernesto Laclau, populismo que expresa en toda su complejidad a la acción política como tal). Esta última se la usa por otros despectivamente juzgando como "populista” políticas demagógicas que simplemente siguen el imperio de la moda, de la opción "corto plazo", o que buscan la simple mayoría electoral de las masas influenciadas por los medios de comunicación para ejercer el poder por el poder, o en función del proyecto nacionalista o autoritario (en general juicio usado por políticos neoliberales). Por su parte, Antonio Gramsci, describe al pueblo dentro de su terminología filosófico política, como “el bloque social de los oprimidos". Fidel Castro considera al pueblo, categoría que usa frecuentemente, a partir de una significación cotidiana, pero describiéndola complejamente a partir de los actores múltiples que lo constituyen, y lo considera como el actor colectivo político fundamental. Aún en los análisis de la obra de Walter Benjamin, en la interpretación por ejemplo de G. Agamben ${ }^{49}$, la categoría de pueblo tiene una significación política polisémica que se extrae de Pablo de Tarso: el "no-pueblo-mío" se opone al "mipueblo", que debe distinguirse del "resto" colectivamente, y singularmente del "meshíakh". ¿Cómo resolver esta tan amplia gama de significados? Pienso que la analogía viene en nuestro auxilio mostrando un ámbito de semejanza entre todas esas palabras referidas a conceptos y momentos políticos distintos, pero advirtiendo que la distinción de los contenidos semánticos de cada uno es analógica ${ }^{50}$.

Primera distinción (Dt1). Quizá la significación más amplia, y por ello válida pero imprecisa, que podría comenzar a bosquejar el ámbito de la semejanza analógica de la

\footnotetext{
${ }^{49}$ Giorgio Agamben, Il tempo che resta, Bollati Boringhieri, Torino, 2000. En especial cuando expone el tema de "Il popolo diviso", el "resto", "il tottto e la parte" (pp. 50-59).

${ }^{50}$ Considérese el diagrama 4, donde cada distinción (Dt1, Dt2, etcétera) indica una significación analógica distinta.
} 
pluralidad de sentido de la palabra pueblo (sentidos que son múltiples distinciones analógicas), sería algo así como lo siguiente: pueblo es la totalidad de la población o de los miembros de un sistema político (al menos en un momento clásico, estabilizado, hegemónico por parte de un "bloque histórico en el poder"51), con historia y lenguas comunes, frecuentemente con cultos o mitos semejantes, dentro de un horizonte cultural próximo, que habita en un mismo territorio (o al menos en un momento en el que se constituyó definitivamente). Este sentido de pueblo constituiría el analogado principal. Todavía no se consideran las contradicciones en el seno del pueblo.

Segunda distinción (Dt2). En un sentido más estricto, y aún crítico, podría denominarse pueblo, en un sentido gramsciano, al "bloque social de los oprimidos", dentro de un sistema social dado. Ese pueblo entra en acción en ciertos momentos estratégicos, lo que A. Badiou llamaría “el acontecimiento" (l'événement) que es cuando

[...] la clase dominante ha perdido el consenso (consenso), no es más la clase dirigente (dirigente), [convirtiéndose] únicamente [en clase] dominante, detentando la pura fuerza coercitiva (forza coercitiva) lo que indica que las grandes masas [el pueblo] se han alejado de la ideología tradicional, no creyendo ya en lo que antes creían ${ }^{52}$.

En este caso el pueblo es el fruto de una ruptura ${ }^{53}$ entre los componentes de la comunidad política, porque habría miembros que serán considerados como "no-pueblo" (o "antipueblo"). Sería una distinción analógica restrictiva de la primera. Es la que Fidel Castro describe detalladamente cuando indica:

Entendemos por pueblo, cuando hablamos de lucha, la gran masa irredenta [...], la que ansía grandes y sabias transformaciones de todos los órdenes y está dispuesta a lograrlo, cuando crea en algo y en alguien, sobre todo cuando crea suficientemente en sí misma [...] Nosotros llamamos pueblo, si de lucha se trata, a los 600 mil cubanos que están sin trabajo [...]; a los 400 mil obreros del campo [...]; a los 100 mil agricultores pequeños [...]; a los 30 mil

\footnotetext{
${ }^{51}$ Según la categorización gramsciana.

${ }^{52}$ A. Gramsci, Cuaderni del Carcere, 3, § 34; Ed.V. Gerratana. Einaudi Ed., Torino, 1975, vol. 1, p.311.

${ }^{53}$ Indicada por G. Agamben en la obra citada supra.
} 
maestros y profesores [...]; a los 10 mil profesionales jóvenes [...]. Ese es el pueblo, el que sufre todas las desdichas y es por tanto capaz de pelear con todo el coraje $\mathrm{e}^{54}$.

Esta significación de pueblo no es solo analógica con respecto a los otros posibles contenidos semánticos de la palabra, sino que por su parte es constitutivamente analógica. Y esto porque siendo un actor colectivo de oprimidos sistémicos de los campos económico, político, de la cultura, etcétera, hoy tiene como base los nuevos movimientos sociales articulados a nuevos partidos políticos críticos. Los movimientos y partidos, tienen distinción analógica en las propuestas de sus reivindicaciones, de sus objetivos (el movimiento feminista es distinto en su proyecto liberador del antirracista, del anticapitalista, del ecologista, del de los pueblos originarios con culturas distintas, etcétera). Los movimientos sociales tienen fines particulares ${ }^{55}$, que deben articularse entre ellos por medio del diálogo, la traducción de sus requerimientos o necesidades, y por la negociación de sus intereses como “fusión de horizontes", que reciben de los nuevos partidos progresistas objetivos nacionales más amplios. Esa totalidad socio-política tiene entonces semejanzas, tanto en sus movimientos sociales como por sus objetivos o intereses, que juegan la función de distinciones analógicas, cuya articulación se torna hegemónicas ${ }^{56}$ cumplida por un actor colectivo que puede tener "contradicciones en su seno".

Tercera distinción (Dt3). Debe tenerse en cuenta, además, que la categoría de exterioridad es esencial en la definición de pueblo con respecto a su segunda significación. Porque el pueblo no es solo el bloque de los oprimidos (el explotado en cuanto alienado y pasivo) en la Totalidad del sistema vigente, sino que igualmente resiste y lucha desde una cierta exterioridad, en un ámbito desde donde el pueblo puede vivir, reconstruirse, fortalecerse para crear, para crecer e irrumpir como actor colectivo de transformación política, cultural, económica, ecológica, en el sistema dominador. El pueblo como exterioridad es la reserva

\footnotetext{
${ }^{54}$ Fidel Castro, "La historia me absolverá”, en La revolución cubana, Editorial Era, México, 1975, p.39

${ }^{55}$ Cada interés particular juega la función de una distinción analógica dentro del interés nacional, que es la pluriversalidad de la semejanza analógica. El proyecto de todo el pueblo contiene una semejanza analógica entonces.

${ }^{56}$ El concepto de hegemonía es intrísecamente analógico, porque el proyecto común (hegemónico y no dominador) cumple con los intereses distintos de los movimientos y partidos que son sus sujetos articulados como el todo del pueblo. Ver Dussel, 20 thesis on Politics, ya cit., tesis 11.17, diagrama 11.1.
} 
cultural y la potencia estratégica esencial ${ }^{57}$. Le llamaremos la plebs, que irrumpe en la historia como un actor colectivo que se presenta ante el sistema político vigente como una fuerza creadora, como una hiperpotentia (más allá de la mera potentia de la comunidad política que se ha fetichizado en su decadencia como represora) que pone en cuestión el sistema de dominación. Es el pueblo en un tercer significado analógico (Dt3). Todo esto lo hemos definido inicialmente en nuestra obra 20 tesis de política ${ }^{58}$, en las tesis 11 y 12 . La presencia crítico destructiva del pueblo como hiperpotentia se constituye como la comunidad política y el actor colectivo del nuevo sistema que surge posteriormente al derrumbe del antiguo sistema dominador. La plebs deviene populus.

Cuarta distinción (Dt4). Habría todavía otra distinción analógica de pueblo, aunque defectiva según mi criterio, la de "populismo" (que E. Laclau no llega a distinguir de popular $)^{59}$, que podría describirse cuando se entiende como miembros del pueblo a todos los habitantes considerados como masa, como "multitud" (en el sentido de A. Negri) bajo la organización de un Estado y en un territorio (Dt1), pero asignándole una opción nacionalista (de derecha o izquierda), donde no se produciría la ruptura entre pueblo y anti-pueblo antes indicada, cayéndose en una ambigüedad criticada por algunos, tan frecuente en Europa como en América Latina y en otros lugares, de líderes carismáticos inescrupulosos, demagogos. A veces se confunde intencionalmente, por parte de los grupos dominantes, a la acción verdaderamente liberadora de líderes populares como meramente populistas, teniendo en cuenta que se ocultaría su voluntad de dominio en un tipo de legitimidad que Max Weber denominaba de carismática.

En este corto artículo no podemos tratar toda la cuestión, solo se intenta indicar que teniendo en cuenta la lógica de la analogía se puede efectuar una descripción y juicio valorativo de estas distintas maneras de conceptuar el pueblo. Lo que permitiría criticar a alguna de posturas en boga y, por el contrario, mostrar la importancia de otras.

\footnotetext{
${ }^{57}$ En el diagrama 6 distinguimos entre el sistema dominador como vigente (A: pueblo como Dt1), como oprimido ( $B: D t 2)$, y el oprimido como exterioridad, como reserva del futuro ( $C: D t 3)$.

58 Véase Dussel, 20 theses of Politics, Duke University Press, Durham, 2008.

${ }^{59}$ Popular se refiere a las distinciones analógicas Dt2 y Dt3, mientras que populista, para nosotros, vuelve a la ambigüedad de referirse al todo social (Dt1) pero definido despectivamente por posiciones liberales o neoliberales como meramente volcada al cumplimiento de una voluntad caprichosa, superficial del pueblo como masa o multitud desde un horizonte cuasi nazi o fascista.
} 


\section{La analogía en el diálogo intercultural y en la descolonización epistemológica.}

La lógica de la analogía incluye también una ética del respeto al Otro/a, una paciencia en el tiempo largo de la discusión para comprender la pretensión de verdad del Otro/a, y la posibilidad de llegar a acuerdos racionales sin que se haya alcanzado la identidad que imposibilita frecuentemente la validez necesaria de las opiniones para el obrar en común.

La hipótesis de una raggione debole en un G. Vattimo, por ejemplo, que ataca la razón dominadora de la modernidad, considerada dogmática y autoritaria, intenta llegar a una ética de la comunicación, pero para ello cae inevitablemente en un cierto escepticismo que pone en cuestión todo tipo estricto de racionalidad, e igualmente niega a la razón crítica, que no es débil y que tiene todo el derecho de expresar una gran narrativa, aunque puede ser épica y no trágica. Por ello se puede perfectamente reformular la cuestión desde la afirmación de una razón analógica, que no es ni débil ni escéptica, en el sentido nietzscheano, y que puede criticar a la razón moderna, encontrando que se trata de una razón unívoca dentro de la lógica excluyente y dominadora de la identidad/diferencia. La semejanza, y no la identidad, permite un mayor ámbito de movimiento para mejor realizar el diálogo constructivo y crítico analógicamente entre las distintas posiciones que conservan un ámbito de semejanza donde la fusión de horizontes de los temas tratados respeten las distinciones sin exigir identidad.

En un horizonte mundial, no meramente eurocéntrico y desde la posición crítica inaugurada por la descolonización epistemológica, la práctica del uso de la lógica analógica es hoy muy fecunda en el llamado "diálogo intercultural”, tan necesario ética, teórica y políticamente. En efecto, las posiciones opuestas a la analogía pueden ser descritas entre los dos límites que podrían ser, contradictoriamente, por a) cuando se piensa que la humanidad logrará gracias al diálogo, o a la violencia, el cultivo de una cultura universal futura, que no podría ser sino un tipo de modernidad como la vivida por Europa desde finales del siglo XV, o b), en su extremo contrario, el fundamentalismo que propugna la yuxtaposición de culturas equívocas que son diferentes al retornar a sus orígenes, y para las cuales la modernidad europea se negaría absolutamente. Entre ambas posiciones, a) la primera, que intenta imponer la pretensión de verdad de la unívoca identidad universal europea, y la segunda, b) que se propone la destrucción de la modernidad, a sus ojos corrupta, imponiendo una equívoca 
posición de la radical, esencialista e irreconciliable contradicción con lo que se juzga como blasfemo y diabólico, se abre el camino, en tercer lugar, c) la analogicidad del diálogo entre las distintas culturas existentes que reconocen la dignidad de las otras, y también de la modernidad.

Más allá de la identidad lógica de la univocidad universalista (de la identidad/diferencia) la pluriversidad de la analogía (de la semejanza/distinción) permite en el iniciar el proceso de diálogo intercultural, honesto y ético en el que cada interlocutor pueda tener una "pretensión de verdad" (truth claim), que intenta alcanzar "pretensión de validez" (validity claim) en los otros miembros de la otras culturas. Dicha validez será legítima gracias a la mediación del consenso a través de una praxis fraterna y en el uso de la racionalidad argumentativa, que puedan llegar al acuerdo por una coincidencia en la semejanza del contenido semántico del contenido en disputa. La "validez"60, no exige identidad. Si se acuerda adecuadamente sobre esa semejanza se avanzará hacia una mayor comprensión que es mutuamente enriquecedora como crecimiento del ámbito en el que se van fusionando los mundos de los interlocutores. No se trata del escepticismo de admitir muchas verdades, sino de la discusión argumentativa de distintas pretensiones de propuestas que guardan una cierta distinción desde la semejanza, pero no identidad, que es imposible ontológicamente. Las distintas posiciones que se enfrentan objetivamente proceden frecuentemente de una complejidad y plenitud inconmensurable de la realidad misma desde mundos diversos, y en

\footnotetext{
60 "Validez" (validity en inglés, Gültichkeit en alemán, “validité en francés), no es lo mismo que "verdad" (truth, Wahrheit, verité). La "verdad" es la referencia (reference en inglés, Bezug en alemán, référance en francés) de la subjetividad cognoscente a la realidad; "validez" es, en cambio, la referencia de un miembro con respecto a la comunidad de comunicación y a la "aceptación" (acceptance en inglés) o no, por parte de los otros miembros de la comunidad, acerca del argumento que se propone para su aprobación o rechazo, para su validación (en inglés sería validate y no verification) o su invalidación (invalidate no es falsification, este último término en el sentido popperiano). La "pretensión de verdad" (truth claim) no es lo mismo que la "pretensión de validez" (validity claim). El tiempo del diálogo, de la honesta discusión, es el tiempo que aunque cada miembro de la comunidad dialogante tiene todos "pretensión de verdad", al correr el tiempo de la discusión de los argumentos que justifican la "pretensión de verdad" serán puestos a prueba. Mientras los argumentos que un miembro propone no han sido aceptados por los otros, no alcanza todavía la "pretensión de validez", ya que tal cumplimiento solo se logra si los oponentes aceptan el juicio como verdadero del primero. En el nivel mundial del diálogo inter-filosófico, intercultural o inter-religioso el tiempo de la "pluriversalidad" es el momento de la vigencia de un reconocido y mutuo horizonte de Semejanza $(\mathrm{Sm})$ pero no de Identidad. De todas maneras puede haber una aceptación de aspectos que eran al comienzo de la discusión heterogéneos o distintos, pero que irán crecientemente alcanzando mayor semejanza, aunque nunca absolutamente idénticos. Esta situación puede madurar durante siglos.
} 
referencia subjetiva a la finitud cognitiva inevitable del ser humano ante la misma realidad de suyo (como diría X. Zubiri) y al sentido fundado en el otro mundo del Otro/a.

Si tomamos, por ejemplo, la experiencia de la "naturaleza" se ha de comprender que en las diversas culturas tiene otro sentido. En la civilización moderna la naturaleza es simplemente la materia del trabajo que puede transformarse gracias a la tecnología, que puede venderse y comprarse como una extensión de tierra, que puede explotarse por la agricultura para realizar negocios en la producción agrícola. Es un objeto a la mano; es un recurso de la razón poiética, instrumental. Es una cosa a disposición del ser humano. En las culturas originarias de América Latina, como la azteca, maya, quechua, tupi-guaraní, etcétera, el ser humano guarda por la Tierra Madre un respeto sagrado. La experimenta como el mundo dentro del cual $^{61}$ el ser humano es solo una parte, hijo/a de la Madre que lo alimenta, lo ha generado y que exige cuidado y veneración porque de Ella procedemos (por la evolución de la vida que es un fenómeno terrestre) y a Ella volveremos. Si hubiera un diálogo intercultural entre miembros de mundos culturales distintos (analógicamente) y se comunicaran el significado de la indicada "naturaleza" habría que tener en cuenta esta distinción polisémica. Se trataría entonces de significados existenciales distintos (analógicos) aunque cuentan con una cierta semejanza (al final la naturaleza es lo no-humano donde nos encontramos estando en su seno, en su interioridad cotidiana; no ante nosotros sino nosotros dentro de Ella). El diálogo intercultural acerca de la naturaleza comenzaría por una cuasi incomprensión abismal, pero poco a poco, en el tiempo de la revelación que cada uno recibe del Otro/a, va abriéndose a una "fusión de horizontes" (diagrama 4), y el ámbito de la semejanza ira acrecentándose. Nunca llegarán a una experiencia existencial unívoca, a la captación idéntica de la significación que el Otro/a otorga a esa experiencia, pero se irá creando un enriquecimiento por progresiva captación de un concepto polisémico en un mundo cada vez más común, en donde es posible una mutua y progresiva comprensión.

\footnotetext{
${ }^{61}$ No es meramente un objeto [ob-yecto], lo arrojado delante del sujeto [sub-yecto], sino que es la totalidad de la biosfera planetaria en la que (dentro de la cual) el ser humano recibió la vida por evolución de dicha naturaleza (metafórica, pero realmente, es nuestro origen, nuestra madre, nuestro hábitat).
} 
Todos los temas o experiencia de una cultura pueden ser dialogados con miembros de otras culturas, y esto permitirá la edificación de una cultura pluri-versal (no uni-versal) ${ }^{62}$ mundial que es lo que se intenta en dicho tipo de diálogo.

El diálogo racional debe tener como principio ético una actitud de respeto de la "pluriversidad analógica" de la humanidad que le permita la progresiva comprensión mutua, aceptando no contradictoriamente la pretensión de verdad de la otra cultura, a la que no se intentará primeramente refutar (es decir falsar $^{63}$ ) sino emprender conjuntamente la larga senda de la lenta pero cada vez más profunda comprensión del sentido de los componentes lingüísticos y conceptuales del otro mundo cultural, para asimilar las experiencias de otras culturas desde la fusión de horizontes en la semejanza, que de todas maneras no alcanzará un consenso idéntico, pero sí un entendimiento amplio, necesario y suficiente para un mundo que se proponga el postulado de la vida y la paz perpetuas.

El método analógico en América latina como camino a seguir en el tipo de diálogo entre distintas culturas del mismo continente, entre las culturas de los pueblos originarios, de los criollos, de los mestizos y de los afros, es necesario, y se trata igualmente de un método para un diálogo analógico entre pueblos de un mismo continente cultural.

\section{La pluriversidad de la Transmodernidad de la Nueva Civilización futura como concepto analógico}

En el largo tiempo del diálogo intercultural la convergencia hacia una Nueva Civilización en una Edad del mundo transmoderna exige tener bien claro el significado de una cultura mundial pluriversal, que no intente la univocidad de la mera globalización de la modernidad transnacionalizada presente, sino una cultura que pueda articular todas las culturas existentes en la semejanza, y la solidaria mutua construcción pacífica de la humanidad que irá subsumiendo los otros distintos aspectos más importantes y valiosos de las culturas regionales, sin necesidad de aniquilarlas al imponerles la identidad de una cultura dominadora del mundo, como lo había imaginado Hegel, que subyugaría a todo el resto. Es

\footnotetext{
${ }^{62}$ No se trata de una cultura universal sustantiva globalizada, sino de la cultura pluriversa mundial. fundamentalista.

${ }^{63}$ La falsification popperiana.
} 
necesario imaginar, durante siglos, el lento proceso de una cultura mundial polisémica en la semejanza, construida por el aporte de la distinción milenaria de las culturas existentes.

Escribíamos hace 45 años:

"Llamamos universalidad [hoy diría "pluriversalidad"] analógica el todo de la humanidad futura unificada en la distinción de sus partes integrantes, donde cada una, sin perder su propia personalidad cultural, pueda sin embargo participar de una comunicación sin fronteras de cerrados nacionalismos. No es la univocidad de una humanidad dominada por un solo Imperio, sino una sola Patria mundial en la libertad solidaria de las partes. Por ello no hay filosofía universal (abstracta, unívoca, ni aún concreta). No hay filosofía sin más ${ }^{64}$. Hay filosofías, la de cada filósofo auténtico, la de cada pueblo que haya llegado al pensar reflexivo, pero no incomunicable sino comunicado analécticamente; y esto porque la palabra de cada filosofía es respetada como distinta por ser analógica" 65 .

Allí se expresaba explícitamente lo que hoy llamamos la pluriversidad mundial (analógica) de una cultura por venir, que irá más allá de la modernidad europea como pretendida cultura globalizada, Edad del mundo que hemos llamado transmoderna. Ese texto fue publicado en 1973.

El concepto islámico de Tawhid indica exactamente la revelación del Absoluto islámico dada a conocer de distintas maneras a los diversos pueblos, lo que indica exactamente la presencia analógica de una revelación distinta para cada comunidad cultural desde una semejanza fundamental. De esta manera no es necesario aniquilar la pretensión de verdad del Otro/a, sino más bien descubrir la semejanza entre las diversas pretensiones distintas de verdad de los participantes en el diálogo intercultural (inter-filosófico).

En la concepción desde la univocidad de la identidad, la propia "posesión de verdad" se impone a los otros dialogantes, ya que el que tiene esta certeza presupone a priori tener que

\footnotetext{
${ }^{64}$ Un poco ésta era la pretensión del gran filósofo Leopoldo Zea, que concebía a la filosofía como "filosofía sin más".

${ }^{65}$ Dussel, Para una ética de la liberación latinoamericana, ya cit., p. 241. Negación de la expresión de Leopoldo Zea.
} 
“defender" de la verdad, no necesariamente por la sola argumentación o ejercicio honesto de una acción ética coherente con la verdad enunciada. En último término, y ante la resistencia del Otro/a, no cabe más que la dominación por la fuerza para mover al otro interlocutor (en última instancia: la guerra) a aceptar la verdad propuesta. Sería la pura expansión tautológica universal de "La verdad" del dominador. El diálogo está de más, y la violencia de las armas es válida para el fundamentalista, en tanto impone la verdad a los que la ignoran. Es una lógica que se torna irracional en tanto se quita al Otro/a la honesta y ética libertad de argumentar, de poder no aceptar los argumentos o de no poder aceptarlos como propios de manera racional, responsable, libremente y con derechos simétricos. La universalidad unívoca que se impone por la coacción es necesariamente dominadora e irracional.

La cultura transmoderna de la futura Edad que se va bosquejando en el presente debe ser fruto de un crecimiento cualitativo de la humanidad, que podríamos indicar en los siguientes estados diacrónicos.

Primer estadio. En el origen de la Modernidad, con la apertura al Atlántico de Europa sitiada por el imperio otomano y la consecuente conquista de América Latina (1492), dicha modernidad subsumió dominando a las culturas originarias de América, constituyendo la estructura dual esencial en la nueva Edad del mundo: modernidad/colonialidad. La modernidad se constituye a sí misma en el mismo instante que subsume a las culturas americanas (durante sus tres primeros siglos) negadas en su exterioridad.

\section{Diagrama 6}

La modernidad se constituye en la dominación de las culturas coloniales

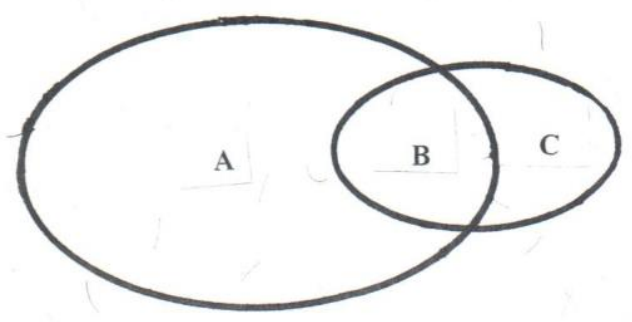


Aclaración al diagrama 6: A) Totalidad. La cultura europea se desarrolla como modernidad. B) Ente subsumido como las culturas coloniales y explotadas por la modernidad. $C$ ) Estructuras que guardan exterioridad a la dominación colonial de la modernidad.

Las culturas no europeas no son respetadas en su alteridad (analógica) sino que son subsumidas $(B)$ negando su exterioridad e incorporándolas al sistema-mundo como parte integrante dentro del horizonte unívoco de la totalidad modernidad, como colonias del sistema capitalista por ejemplo, que se alimenta de la extracción de riqueza ajena produciendo la alienación de las otras culturas. La llamada Edad moderna se produce y reproduce explotando de las colonias saberes, recursos, riquezas, trabajo, tecnología, tipos de alimentos, etcétera, que permitirán a Europa constituirse como el centro modernizante de la nueva Edad.

Segundo estadio. Después de aproximadamente cinco siglos de colonialidad, los pueblos, las culturas periféricas, dominadas y declaradas "atrasadas" con respecto a la moderna Europa (y desde la llamada Segunda Guerra Mundial prolongada por Estados Unidos) comienzan una primera "toma conciencia" de su estado de subdesarrollo que las estructuras de dominación modernas han organizado para producir su inevitable situación de pobreza (en todos los niveles culturales o civilizatorios). Son los movimientos de liberación nacional en África y el Asia, que se anticiparon desde comienzos del siglo XIX en América Latina. Solo en la segunda parte del siglo XX dichos pueblos toman una segunda toma de conciencia más profunda que la producida en una primera emancipación política más superficial; se trata de negar la introyección de la modernidad en la conciencia de las clases dominadoras de las élites en las colonias (o postcolonias) que reproducen la cultura y el ethos civilizador metropolitano, moderno. Esta segunda emancipación la hemos denominado la descolonización epistémico cultural.

Tercer estadio. Tomando como lugar de enunciación (locus enuntiationis) no el momento subsumido y meramente dominado del mundo colonial ( $B$ del diagrama 6 ) y menos aún la posición del mismo mundo moderno (A del diagrama $)^{66}$, sino la exterioridad despreciada por

\footnotetext{
${ }^{66}$ Cuando las élites criollas coloniales o postcoloniales adoptan una actitud "modernizadora" (es decir, el pretender aplicar a su cultura y pueblos el modelo civilizatorio de la modernidad europea), solo producirán una praxis contradictoria ya que pretenden desarrollarse tomando a la misma modernidad como ideal civilizatorio siendo que esa modernidad tiene como momento constitutivo la colonialidad de sus periferias. Una periferia sin
} 
la modernidad (y por ello no destruida o explotada porque ignorada, pero al mismo tiempo menos contaminada ${ }^{67}$ ) ( $C$ del mismo diagrama $)$, el crítico del mundo periférico deberá comenzar una tarea de reconstrucción arqueológica de su propia memoria cultural y popular. Deberá rehacer "a contrapelo" (diría Walter Benjamin), desde los oprimidos vencidos por la modernidad, desde la memoria o la historia de su núcleo ético mítico de su propia cultura (como lo enunciaba P. Ricoeur), las gestas de su milenaria civilización (p. e. de la China, del Sudeste asiático, del área indostánica, del mundo islámico, del África bantú, de los pueblos originarios latinoamericanos, etcétera), de sus saberes, de sus técnicas, de sus economías, política, poesía, arte, etcétera, muchas de las cuales son más antiguas que la modernidad y que siguieron resistiendo e inventando nuevos usos y costumbres en la Edad Moderna (pese a su colonialidad). Esas culturas no son esencias idénticas eternas; son estructuras culturales que evolucionan con la vida de los pueblos y no pueden volver a reproducir su pasado en el futuro. Pero sí pueden seguir viviendo y evolucionando su mundo distinto. Esta tarea reconstructiva no puede hacerla el científico o sabio moderno europeo, porque es ajeno, es un extranjero, no conoce las lenguas coloniales como lengua materna, no ha comido sus alimentos educando sus papilas gustativas a su cocina, no ha vivido su sensibilidad, sus climas, sus vestidos, sus hogares. Son procesos olvidados, invisibles y juzgados atrasados, toscos, bárbaros aún por muchos miembros de los propios pueblos periféricos silenciados sucesivamente desde finales del siglo XV (comenzando por América Latina, y continuando por India, el Sudeste asiático, el mundo islámico y el África).

Cuarto estadio. Para construir una nueva civilización transmoderna, un nuevo mundo es necesario la información por medio del diálogo intercultural con las otras culturas que sufrieron la misma dominación moderna, para aprender otros valores, otras literaturas, otras historias, otras economías, políticas, estéticas, otras maneras de practicar los géneros, etc. No se trata de imitar unívocamente a otra cultura; se trata ahora de un diálogo donde se produce la fusión de horizontes de la que hemos ya explicado su sentido (diagrama 5). Será necesaria

colonias nunca podrá imitar a la modernidad/colonialidad. Para colmo, la misma vanguardia revolucionaria postcolonial asume frecuentemente las estructuras epistémicas de la modernidad (y aún los movimientos fundamentalistas que pretenden oponerse radicalmente a la modernidad). Es una colonialidad de segundo nivel, o una inversión de la anterior inversión muy sutil y generalizada.

${ }^{67}$ Como pueden ser las lenguas autóctonas de los pueblos colonizados, sus mitos, sus ritos, su estética, su ética, el respeto a la Madre Tierra, los vestigios ancestrales de prácticas económicas, políticas, familiares, de género, etcétera. 
la traducción de lenguajes, usos, actitudes, mundos como explica Boaventura de Sousa Santos. Se trata de practicar la analogia fidei en un plano mundial. El diálogo donde las culturas aprenden de otras culturas teniendo conciencia de la distinción analógica de cada tema tratado: ni identidad ni equivocidad. Pero aprende una cultura de la otra no por dominación o imposición de una sobre otra, sino desde la simetría de derechos, sin violencia, en un diálogo razonable (racional), que va escogiendo, decidiendo lo que de la otra cultura me es conveniente. Y entre esas culturas no se trata solo de un diálogo Sur-Sur de excolonias con excolonias, sino también con la cultura moderna que no es universal, sino particular, provinciana, que se impuso sin embargo con "pretensión de universalidad" al extraer recursos de todas las culturas distintas desde su univocidad universal impuesta por la violencia, y no con la justicia en beneficio del bien común de la humanidad, sino como acumulación de la riqueza mundial usufructuada solo por el centro, por Europa -y actualmente también por Estados Unidos.

No debe ser un diálogo fundamentalista que niegue toda validez a la modernidad, sino que sepa diferenciar lo que conviene a la propia cultura del Sur y lo que le es pernicioso. Sin fundamentalismo que niega totalmente la modernidad; pero igualmente sin la colonialidad del saber, del ser, del existir, que se niega a sí mismo. Descolonización cultural y epistemológico-tecnológica que tiene un proyecto distinto para una civilización nueva futura, no para retornar a una tradición del pasado imposible de ser repetida, sino hacia otra que debe continuar los trazos ontológicos, éticos, culturales de la propia tradición, que está viva, en una nueva civilización futura. Ni negación de la tradición; ni sustancializar la eternidad inexistente de una tradición a la que debería retornarse; sino la creación dialéctico-analógica de una nueva totalidad que tome de la tradición lo mejor, lo esencial y que innove en una nueva totalidad distinta. Semejante a las de las etapas anteriores de la tradición, pero distinta y nueva época de la misma tradición.

Quinto estadio. Se trata entonces del tema ya bosquejado. A partir del diálogo mundial del Sur-Sur y Sur-Norte, y la producción de mediaciones instrumentales y un cambio éticoontológico de la subjetividad, se debe continuar un crecimiento vital de las culturas postcoloniales descolonizando sus interpretaciones, sus epistemes, sus tecnologías, sus proyectos en todos los niveles o campos (no solo económico, sino igualmente político, 
cultural, de género superando el patriarcalismo, más allá del racismo blanco, del suicidio ecologismo de una interpretación secularista y meramente cuantitativa de la naturaleza, etcétera) siendo procesos con distinción analógica, es decir, distintos no unívocos. Cuando alguien enuncie el tema de los derechos humanos en América Latina debe conocer la distinción analógica de ese concepto en la tradición del derecho y la centenaria filosofía árabe, por ejemplo. Y así todos los componentes de una cultura, de una civilización, de las estructuras económicas, políticas, etcétera.

\section{Diagrama 7}

Crecimiento desde cada cultura (con distinción analógica) y el pasaje dialéctico a una nueva Civilización mundial, a una nueva Edad del Mundo

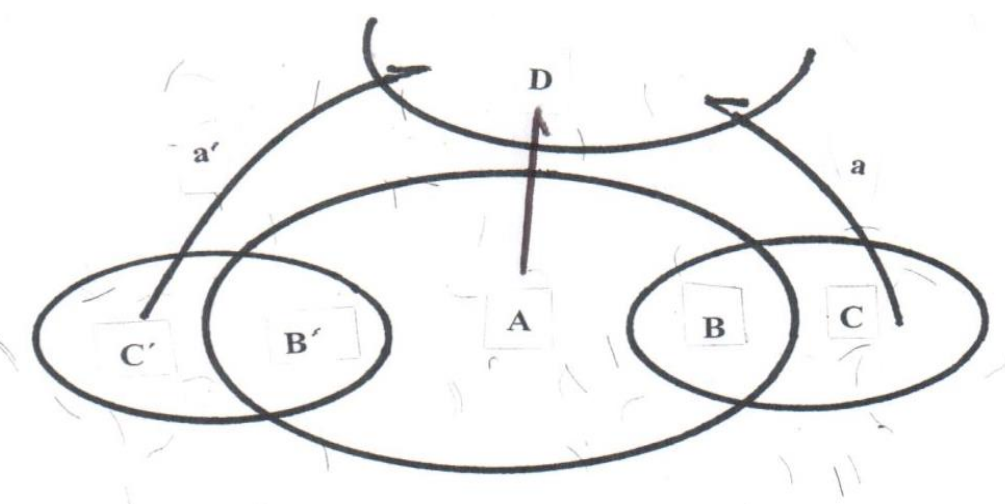

Aclaración al diagrama 7. A) La modernidad, la cultura en la Edad Moderna. B, B', etcétera) Momentos dominados, explotados o alienados subsumidos como mediaciones de la modernidad. $C$, $C^{\prime}$, etcétera) Momentos que guardan exterioridad y son el punto de partida del crecimiento histórico (procesos analógicamente distintos). D) Pluriverso cultural mundial o Edad transmoderna (la semejanza analógica). Flechas $a$, $a^{\prime}$, etc.) Crecimiento distinto de cada cultura. Flecha de A a D) Proceso dialéctico de una totalidad vigente $(A)$ a otra totalidad futura $(D)$. Este proceso dialéctico como pasaje (Übergang), es simultáneamente analógico en tanto que en $D$ hay componentes que no se daban en $A$ (hay entonces semejanza entre ambos: $A$ y $D$ ), y que no estaban ni siquiera en potentia (la dynamis aristotélica) en $A$. Es decir, era entonces imposibles si fuera meramente un pasaje unívoco de identidad. Pero la intervención de los aportes desde la exterioridad de la modernidad (indicados por $C$, $C^{\prime}$, 
etcétera, y por las flechas $a$, $a^{\prime}$, etcétera) transforman el proceso en una creatio ex nihilo (desde la nada $^{68}$ ) de $A$ a $D$.

Sexto estadio. El sistema futuro $(D)$, la Edad del mundo posterior a la Edad moderna, no será otra modernidad plenamente realizada (J. Habermas), ni una alter Modernidad (Antonio Negri), ni posibles nuevas modernidades a partir de cada cultura del Sur (el filósofo marroquí Taha Abdurahman), ni una modernidad no capitalista (B. Echeverría), etcétera. Se trata en cambio de otra Edad del mundo, otro proceso civilizatorio, otra subjetividad personal y colectiva de los pueblos, que será la superación de la modernidad, así como ésta en Europa (solo en Europa) fue la superación del feudalismo germano medieval (recordando que ninguna otra cultura en la historia mundial fue feudal). Hemos denominado todavía sin designación positiva a esa Edad del Mundo: la Transmodernidad, para distinguirla de la Postmodernidad. Esta última ha sido un positivo paso delante de la modernidad en su agonía, que produjo una autocrítica parcial de sí misma. La Postmodernidad, agónico y el último movimiento cultural de la modernidad todavía, tiene como lugar de enunciación a la misma modernidad, y sus creadores y cultores son todavía modernos, aunque críticos de los excesos de su propia cultura. La Transmodernidad se construye en cambio con miembros críticos que piensan, actúan y proyectan desde fuera del horizonte moderno, desde otra geopolítica, desde otro mundo ignorado, negado, explotado, desde el "no-ser" parmenídico.

Pero el creador de la Transmodernidad, de una nueva Civilización, no es un fundamentalista que niega meramente la modernidad, ni un atrasado o tradicional que se moderniza, ni alguien que intenta reproducir desde cada tradición una modernidad propia irrepetible. Gracias a la superación de la provincialización de la modernidad (para lo cual hay que primero negarle su pretensión de universalidad) se abre la posibilidad futura de una

\footnotetext{
${ }^{68}$ Ignorándolo toda la tradición marxista, incluyendo F. Engels, Karl Marx indica que el "trabajo vivo" alienado como "trabajo asalariado" en el "plus-tiempo" de "plus-trabajo" opera una "creación de valor desde la nada" (Schöpfung des Wertes aus Nichts) del capital: es el "plus-valor" (véase Dussel, El último Marx (1863-1882), Siglo XXI, México, 1990, § 9.3, pp. 368ss). La trans-ontología (metafísica o ética en el sentido de E. Levinas) de la creación es la última instancia del pensamiento del gran crítico del capital. Pienso que no pudo dejar de usar una categoría propia de su tradición semita (era de una familia de rabinos con tradición judía de más de cuatro siglos, por parte de padre alemana y de madre holandesa). Aquí podría aplicarse la lógica de la analogía entre a) el Ser del trabajo vivo, que es "la fuente creadora (schöpferische Quelle) del valor" (el trabajo vivo es el creador), y b) el ser del ente: el "plusvalor", que es un mero ente (es decir, la creatura).
} 
civilización, un mundo, una cultura, una Edad mundial pluriversal (en la que consiste la semejanza de la analogía), donde se respeta la distinción de cada cultura diversa, pero se construye, con firme esperanza, una fusión de los horizontes distintos de las diversas culturas donde puedan ir ganando mayor semejanza, en la mutua comprensión, en la complementación valorativa, en la tolerancia. Lo contrario sería la identidad, de por sí imposible, pero que se constituiría en un final empobrecimiento de la humanidad, ya que se impondría un solo pueblo su propia cultura idéntica a sí misma, la correspondiente del dominador del mundo, y que imperaría su sola lengua, su sola historia, su solo mundo mítico, su sola poesía:

Ese pueblo (Volk) es en la historia mundial de esa época [...] el dominador (herrschende). Contra ese su derecho absoluto (absolutes Recht), como portador que es en el presente del desarrollo del Espíritu del mundo (Weltgeistes), son los Espíritus de los otros pueblos sin derecho alguno (rechtlos $)^{69}$.

Sería la culminación de la Voluntad de Poder nietzscheana, que se autoafirmaría político mundialmente como unívoca, proclamándose como la verdad absoluta excluyente globalizada. Se trataría de la soledad de una unanimidad tautológica. ¡El aburrimiento infernal total del totalitarismo moderno fetichizado!

La analogía nos abre, en cambio, la senda hacia una racionalidad no solo discursiva o dialogante sino también por semejanza pluriversal (no universal), que permite la convivencia, el reconocimiento, frágil inevitablemente pero activamente tolerante, y abierto, donde muchos mundos se solidarizan recreándose, y así permiten la aventura innovadora de la inesperada y creadora interpelación del Otro/a, que para ser otro/a necesita cuidar ${ }^{70}$ su espacio, su distinción, y no la mera diferencia interna y funcional en la totalidad unívoca muerta en la certeza de una repetición tautológica. Analogía que es creación de lo nuevo sin

\footnotetext{
${ }^{69}$ Hegel, Grundlinien der Philosophie des Rechts, § 348; Hegel Werke, Theorie Werkausgabe, Suhrkamp V., Frankfurt, 1970, vol. 7 p. 506. ¡He aquí la culminación política de la lógica de la identidad/diferencia!: “[...] als unmittelbaren Offenbarung hat er zum Prinzip die Gestalt des substantiellen Geistes als der Identität [...]" (Ibid., § 353, p. 508: “[...] como revelación inmediata tiene él [el Espíritu del mundo] como principio la figura sustancial del Espíritu, en cuanto [principio] de la Identidad [...]").

${ }^{70} \mathrm{El}$ "souci de soi" diría en francés un M. Foucault.
} 
perder la belleza de la distinción de la pluralidad en la unidad o comunidad de la semejanza polisémica, que une pero no domina, que permite el diálogo y que no exige el olvido a la propia distinción milenaria cultural, augurando milenios futuros en mayor convergencia. No es retórica disputa argumentativa abstracta como competencia destructiva del Otro/a, sino complementariedad dialógica y armónica que reconoce la alteridad. 